\title{
DO USO DE CELEBRIDADES EM PUBLICIDADE ${ }^{1}$
}

\author{
The use of celebrities in advertisement
}

\section{El uso de celebridades en la publicidad}

Celso Figueiredo Neto ${ }^{2}$
Yan Prado Lopes Silva

\section{Resumo}

Diversas marcas têm se utilizado de celebridades para anunciarem seus produtos. $\mathrm{O}$ presente trabalho tem por objetivo, a partir do referencial teórico da retórica e do levantamento bibliográfico nacional e internacional, estabelecer um sistema de categorização das celebridades de maneira que se perceba uma tipologia das celebridades, categorizadas por importância no sentido de valor na construção de marcas. Entende-se que tão mais eficaz será uma mensagem quanto mais crível for seu ethos. Dentre os elementos que compõem o ethos de uma marca um dos mais diretos, claramente discerníveis e amplamente utilizados é a celebridade. A subdivisão das autoridades utilizadas em publicidade é aqui proposta em três grupos: stricto, lato e presença conforme características das celebridades e sua relação com marca, produto e mensagem publicitária.

Palavras-chave: publicidade, retórica, celebridade, autoridade, branding.

\section{Abstract}

Several brands have been using celebrities to advertise their products. This work aims, from the theoretical rhetoric and the national and international literature, to establish a system of categorization of celebrities that shows a typology of celebrities, categorized by importance in the sense of value in building brands. It is understood that such a message will be more effective the more credible is their ethos. Among the elements that make up the ethos of a brand one of the most direct, clearly discernible and widely

\footnotetext{
${ }^{1}$ Uma versão anterior e distinta desse texto foi apresentada e consta dos anais do XXXII Congresso da Intercom de 2009.

${ }^{2}$ Doutor em Comunicação e Semiótica pela PUC-SP, professor pesquisador da Universidade Presbiteriana Mackenzie, líder do grupo de pesquisa Pario, editor da revista Inovcom. E-mail: kekofig@ gmail.com ${ }^{3}$ Graduando em Publicidade e Propaganda pela Universidade Presbiteriana Mackenzie, bolsista do programa de Iniciação Científica, PIBIC Mackenzie. E-mail: yan_pls@hotmail.com
} 
used is celebrity. The subdivision of authorities used in advertising is proposed here into three groups: stricto, lato and presence, as features celebrities and their relationship with the brand, product and advertising message.

Keywords: advertising, rhetoric, celebrity, authority, branding.

\section{Resumen}

Varias marcas han utilizado a celebridades para publicitar sus productos. El presente trabajo tiene como objetivo, a partir del marco teórico de la retórica y del levantamiento bibliográfico nacional e internacional, establecer un sistema de categorización de las celebridades de forma que se comprenda una tipología de las celebridades, categorizadas por importancia en el sentido de valor en la construcción de marca. Se entiende que esto será un mensaje más efectivo quanto más creíble sea su ethos. Entre los elementos que componen el ethos de una marca uno de los más directos, claramente discernible y ampliamente utilizado es la celebridad. La subdivisión de las autoridades utilizado en la publicidad se propone aquí en tres grupos: stricto lato y presencia según las características de la celebridad y su relación con la marca, producto y mensaje publicitaria.

Palabras-clave: publicidad, retórica, celebridad, autoridad, branding.

\section{INTRODUÇÃO}

Este artigo destina-se a investigar o uso das celebridades pela publicidade e tentar estabelecer um critério de simples utilização que defina a importância, baseada no poder persuasivo da celebridade na publicidade. Sabe-se que o uso de celebridades com efeito de autoritas remonta ao princípio da atividade publicitária. Cartazes anteriores à era da comunicação de massas já se serviam de figuras de destaque para associar seu apelo popular a mensagens ora de cunho comercial, publicitário, ora de cunho ideológico, como propaganda. A máquina da propaganda de guerra foi generosa em imagens de seus líderes em situações alentadoras. Apenas a título de curiosidade, apresenta-se abaixo três posters contemporâneos, veiculados durante a II Grande Guerra, cada um deles destacando o líder de uma das principais nações envolvidas no conflito que extirpou a vida de mais de 59 milhões de pessoas. 
Do uso de celebridades em publicidade

de Celso Figueiredo Neto e Yan Prado Lopes Silva

Fig. 1 - poster Churchill

Fonte: Guity Novin - A History of Graphic Design

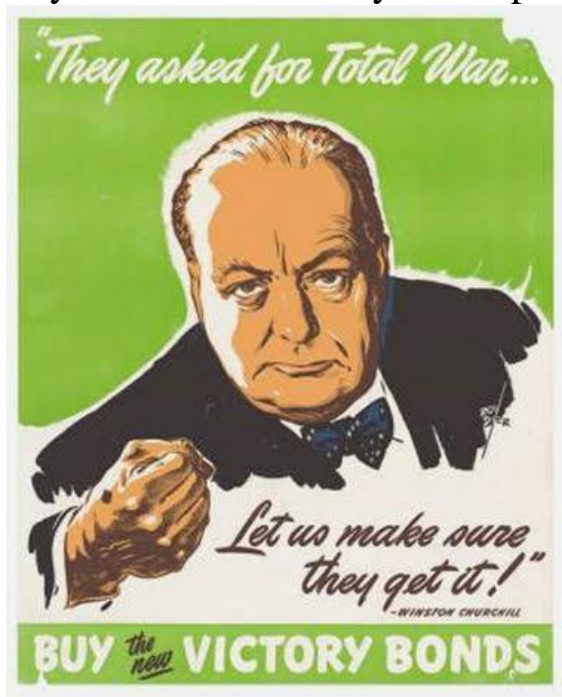

Fig. 2 - Poster Stalin

Fonte: Guity Novin - A History of Graphic Design

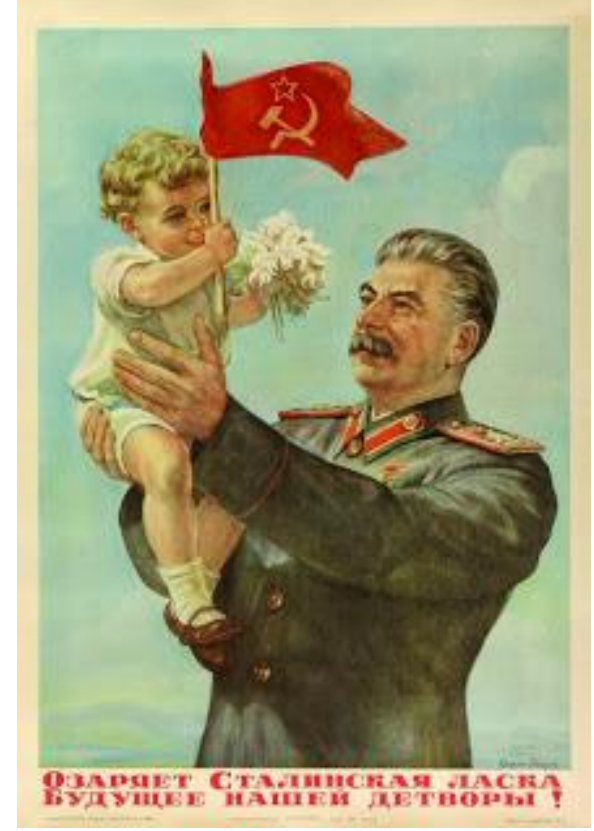


Fig. 3 - Poster Hitler

Fonte: Guity Novin - A History of Graphic Design

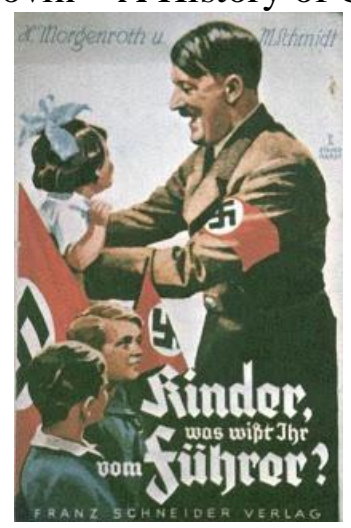

O poder persuasivo dessas figuras não pode ser minimizado, embora, é claro, não se deva debitar à propaganda política número tão colossal de mortes. De qualquer modo, não se poder deixar de notar que as nações que tiveram fama de terem seus exércitos mais cruéis, inclusive contra seus próprios cidadãos por meio de sua polícia política, são as que investiram em imagens de seus líderes em momentos que transmitem mensagens de amor e apreço pela família. Curiosa menção em época na qual o esforço de guerra praticamente eliminou os homens adultos dos países.

Da propaganda à publicidade o uso das celebridades tem sido uma constante desde a expansão da indústria cultural e a consequente espetacularização da sociedade (DEBORD, 1997). Artistas de cinema, personalidades dos esportes, figuras da sociedade tem sido, desde então, utilizados pela publicidade no processo de construção das marcas, emprestando seu ethos a produtos e serviços como estratégia de diferenciação e associação com elementos subjetivos diferenciadores.

Do esmorecimento do fetiche da mercadoria à perda de apelo da própria mercadoria, pode ser resumido o percurso de diversas marcas no mercado. É fato que o mercado foi invadido por similares, variantes, novos modelos, novas cores, embalagens que foram aos poucos esgotando o interesse do consumidor por essa palavrinha mágica, o "novo", ao mesmo tempo em que desnudou uma realidade bastante mais complexa dentro do sistema de consumo: o próprio esgotamento da mercadoria. O que se vê é cada vez mais consumidores desinteressados, distanciados, desconectados dos apelos de consumo que vem se repetindo desde os gloriosos anos 50. Época de ouro da publicidade em que cada novo eletrodoméstico prometia (e em geral cumpria) uma revolução no lar. 


\section{FUNDAMENTAÇÃO TEÓRICA}

O processo de construção de marcas é resultado de uma ampla variedade de estímulos que vão da publicidade à experiência do consumidor com as marcas, passando pelo poderoso WOM - world of mouth, no Brasil conhecido como o boca a boca. O conjunto de teorias mais amplamente adotado para compreender os processos de construção de marca é o chamado branding.

Clunas (1999) observa que uma capacidade inigualável para o consumo tornouse o fio condutor na história da modernidade europeia, ocupando um lugar que antes era reservado para a produção e progresso tecnológico. A marca, por sua vez, é estudada a partir de uma variedade de perspectivas teóricas, entre as quais o branding.

Wengrow (2008) esclarece que "Commodity branding, in turn, is studied from a variety of theoretical, disciplinary, and applied perspectives, including that of a specialized body of academic research on consumer culture and marketing ${ }^{4}$,

Arnould e Thompson inserem a questão do branding dentro do universo da Teoria da Cultura de Consumo, na qual:

The disciplinary pioneers of CCT encouraged investigation of the contextual, symbolic, and experiential aspects of consumption as they unfold across a consumption cycle that includes acquisition, consumption and possession, and disposition processes and analysis of these phenomena from macro, meso, and micro theoretical perspectives (ARNOULD and THOPSON: 2005)

Por outro lado, verificou-se que nem sempre uma celebridade é, efetivamente, motor que gere o impacto esperado, não obstante a sociedade em que vivemos, na qual se venera e explora-se a imagem de indivíduos midiáticos até seu esgotamento. Ainda assim, é necessário entendermos mais adequadamente o papel das celebridades na sociedade do espetáculo como bem demonstrou Gui Debord:

O caráter fundamentalmente tautológico do espetáculo decorre do simples fato de seus meios serem, ao mesmo tempo, seu fim. É o sol que nunca se põe no império da passividade moderna. Recobre toda a superfície do mundo e está indefinidamente impregnado de sua própria glória.

A sociedade que se baseia na indústria moderna não é fortuita ou superficialmente espetacular, ela é fundamentalmente espetaculoísta. No espetáculo, a imagem da economia reinante, o fim não é nada, o desenrolar é tudo. O espetáculo não deseja chegar a nada que não seja ele mesmo. (DEBORD 1997: 17)

\footnotetext{
${ }^{4}$ Branding, por sua vez, é o estudo a partir de uma variedade de perspectivas teóricas, disciplinares e aplicada, incluindo a de um corpo especializado de pesquisa acadêmica sobre cultura de consumo e marketing (trad. nossa).
} 
Essa afirmação egocentrada parece ser feita na medida para a atividade publicitária. Associação do nome, da imagem, da penetração de uma celebridade no universo do produto passou, curiosamente, a ser vista como um graal da relevância publicitária, ou seja, utilizar-se de uma estratégia comunicacional vazia per se serviu para tornar relevante o vazio da publicidade.

Por esse motivo, diversos estudiosos debruçaram-se sobre a questão da celebridade, vez que sua capacidade de fomentar consumo e preferência se tornou aceitas no mercado.

Uma revisão teórica acerca do assunto traz à tona os trabalhos de Roy, S, Gammoh, B, \& Koh (2012) que consiste em uma previsão com relação à eficácia do uso de celebridades endossadoras em campanhas de comunicação, tomando como base as, denominadas pela pesquisa, "fontes de credibilidade" (OHANIAN, 1990) e a "teoria do equilíbrio" (HEIDER, 1958), também chamada de "balance theory". Além disso, retomamos considerações das pesquisas de Junokaitè, Kamilè; Alijošienè, Sonata; Gudonavičienè, Rasa (2007) e Ruihley, Brody J.; Runyan, Rodney C.; Lear, Karen E (2010) que, respectivamente, nos forneceram informações acerca de possíveis soluções para o processo de escolha de uma personalidade, e sobre a utilização de esportistas como figuras midiáticas e, nesse sentido, ferramentas de comunicação.

As "fontes de credibilidade" (OHANIAN, 1990), utilizadas na pesquisa de Roy, S, Gammoh, B, \& Koh (2012), tem como propósito a definição de três dimensões de uma celebridade (fonte de informação) confiável, e como essas dimensões afetam o consumidor no processo de comunicação. Essas dimensões são: confiabilidade (pode ser entendida como substancial pelos consumidores, que podem associar a ação de anunciar uma marca, feita por uma personalidade, com uma mera compensação monetária); experiência ou perícia e atratividade, sendo que para se criar um anúncio eficiente com a presença de figuras midiáticas o autor acredita que é necessário um processo de congruência (match-ups) entre personalidade e produto anunciado, entre celebridade e mensagem apresentada e entre personalidade e consumidor, levando em conta as dimensões citadas.

(MCCRECKEN, 1989; apud ROY, S.; GAMMOH, B. \& KOH, 2012), definem uma celebridade endossadora como sendo "um indivíduo que aproveita de seu 
reconhecimento público em nome de um bem de consumo, aparecendo com ele em algum tipo de publicidade."

Além disso, o autor ainda coloca as figuras midiáticas como detentoras de vários significados para o consumidor, oferecendo uma gama de traços de personalidade e estilo de vida que, devem ser transferidos para o produto anunciado, sendo esse o objetivo dos marqueteiros e publicitários ao utilizar esse recurso na comunicação.

Já a "teoria do equilíbrio" (HEIDER, 1958), é derivada de um estudo de psicologia social que lida com as relações interpessoais, o desenvolvimento e as transformações das atitudes referentes às tríades relacionais [celebridade endossadora, consumidor e produto (E-C-P), dando nome às siglas e celebridade endossadora, consumidor e mensagem (E-C-M)]. A essência da teoria coloca as pessoas como indivíduos que tentam buscar um equilíbrio em suas relações interpessoais e suas atitudes perante esses relacionamentos.

Mowen (1980) sugeriu que a solução para a escolha de uma celebridade esta na descoberta da relação entre celebridade endossadora (fonte), e o consumidor (receptor), e para isso, sugeriu seis possíveis relações entre duas entidades da "Teoria do Equilíbrio" (HEIDER, 1958) são elas: consumidor-endossador (C-E), consumidorproduto $(\mathrm{C}-\mathrm{P})$, consumidor-mensagem $(\mathrm{C}-\mathrm{M})$, endossador-produto $(\mathrm{E}-\mathrm{P})$, endossadormensagem (E-M), e produto-mensagem (P-M). Sendo as três primeiras, atitudes ou sentimentos de relação, e as três últimas unidades de relacionamento.

Para Mowen, o físico atrativo de uma celebridade influencia diretamente a relação entre consumidor e endossador, a confiabilidade a relação entre endossador e mensagem, a perícia a relação entre endossador e produto, e a credibilidade a relação entre produto e mensagem.

Além disso, Mowen (1980) traz algumas considerações e descobertas feitas por outros pesquisadores como: McGuire (1969), que constatou que uma fonte (celebridade) simpática teria um impacto positivo, em termos de crença e persuasão, sobre o receptor (consumidor), Friedman and Friedman (1979), que descobriram que uma celebridade não possui o mesmo impacto para todo tipo de produto. Outros estudos apontaram que marcas anunciadas e celebridade que possuírem congruência obterão um impacto positivo sobre a lembrança (MISRA \& BEATTY, 1990), e a atitude do consumidor (KAMINS \& CUPTA, 1994; TILL et al.,2008). 
Liu (2007) descobriu que celebridades com alta atratividade e pouca congruência com o produto tem mais influência sobre a intenção de compra do que uma personalidade com pouca atratividade e alta congruência com o produto; e Mowen (1980) constatou que o nível de atratividade de uma celebridade influencia no efeito de congruência entre endossador e produto, e, consequentemente na atitude de relação do consumidor para com o produto, medida pela intenção de compra.

De acordo com a teoria "Meaning Transfer" (MCCRECKEN, 1989) as celebridades causam um impacto maior e possuem uma maior congruência com produtos ligados ao seu âmbito de trabalho, pois esses possuem características presentes e necessárias no cotidiano de tal personalidade endossadora, o que facilita $o$ reconhecimento e a atitude positiva do consumidor frente à oferta.

Portanto, o ideal segundo esse trabalho, seria uma celebridade atrativa, confiável e congruente a mensagem e ao produto ofertado.

Belch (2008) acreditam na existência de uma fonte de atributos que possuem determinados modos de recebimento, modos esses que representam a influência dessas características sobre o receptor (consumidor) e suas atitudes de comportamento através de processos chamados de internalização.

Segundo os autores, existem três atributos essenciais, que uma celebridade deve conter, para auxiliar um impacto positivo da campanha sobre o consumidor, e consequentemente são eles que devem ser levados em consideração como critérios de escolha das personalidades para uma determinada campanha (BELCH, 2008), são eles:

\section{1-Credibilidade:}

Descrita como a percepção, por parte do consumidor, da perícia e da confiabilidade que uma celebridade possui, a credibilidade possui influencia sobre a aceitação dos consumidores.

Além disso, a credibilidade pode aumentar a capacidade de aceitação do produto, marca ou empresa por aqueles que tinham uma visão negativa desses, pois inibe os argumentos negativos dos consumidores, apresentando outros argumentos, aumentando a aceitação da mensagem, e consequentemente seu poder de persuasão.

\section{2-Atratividade:}

A celebridade deve ser atraente em aspectos como: aparência física, capacidade intelectual, competência atlética e estilo de vida. 
Esse atributo inclui aspectos como familiaridade, semelhança, simpatia e gostos semelhantes entre os consumidores e as personalidades, que podem aumentar a memória dos consumidores com relação à marca.

O físico atraente de uma personalidade determina o grau de impacto de uma determinada comunicação, através de um processo denominado identificação, ou seja, quando a influência exercida pela figura midiática é aceita, por uma vontade de ser a própria celebridade, por parte do consumidor (por querer se identificar).

Para (FRIEDMAN, TERMIN \& WASHINGTON de 1976), fontes fisicamente atraentes tem um maior poder de transformação de crenças e formação de intenção de compra.

3-Poder ou capacidade de transferência de significado da celebridade para a marca:

Geralmente, o principal objetivo de uma empresa, ao utilizar uma personalidade como ferramenta de divulgação em sua campanha é a transferência de características dessa figura midiática para o produto ou a marca anunciadora; e para que esse processo seja efetivo e impactante, é necessária a existência de uma semelhança entre as características do endossador e do contratante de tal serviço, em aspectos como: personalidade, posicionamento perante a sociedade e "estilo de vida".

Nesse sentido, podemos dizer que, um consumidor se identifica com um determinado produto por este estar sendo anunciado por uma celebridade que possui perfil semelhante ao dele, a medida que, com isso, o objetivo do consumidor é ser como a personalidade endossadora, e para isso, ele acredita que deve comprar e utilizar o produto ou serviço. Esse processo de adaptação e reconhecimento é denominado cumprimento, e se torna eficiente quando, como foi dito, a figura midiatíca consegue proporcionar uma recompensa ao consumidor que utilizar o produto que ela está anunciando, apenas pelo fato do mesmo estar sendo anunciado por essa celebridade e ela conseguir transmitir características positivas de sua personalidade ao produto, e consequentemente ao usuário dele.

$\mathrm{Na}$ outra ponta, a do consumidor, o processo que se percebe ao assistir à televisão, em especial nos canais abertos, é o uso quase que indiscriminado das celebridades para vender de tudo, de cerveja a aparelhos de massagem, de eletrodomésticos à moda jovem; de eletrônicos a panelas e utensílios para o lar... Curioso notar que essas celebridades anunciantes raramente têm um elo entre sua especialidade, ou algum campo onde seu conhecimento possa ser considerado relevante 
e as características do produto anunciado. É mais comum vermos elo entre o produto anunciado e o personagem que determinado ator está representando na novela naquele momento. Há, portanto, confusão entre pessoa e personagem, denotando a falta de personalidade pública de um grupo bastante representativo de atores.

Essa eclosão no uso de celebridades mais ou menos ocas indicia uma nova fase de indiferença, dessa vez em relação às próprias celebridades em um movimento de diluição da importância pelo excesso de exposição que já vimos acontecer com os produtos e com a própria publicidade. É nessa perspectiva que o atual artigo se insere.

Diante do uso de celebridades as mais variadas, pelos mais diversos setores, por meio da indústria da comunicação, entende-se ser pertinente a proposição de um modelo simples e funcional para avaliação da pertinência e qualificação no uso de celebridades em publicidade.

\section{PROPOSTA DE SISTEMA CLASSIFICATÓRIO DAS CELEBRIDADES POR POTENCIAL DE EFICÁCIA}

Partamos, então, do princípio retórico que sustenta o uso da personalidade pública para apoio à marca. Dentre as três dimensões do discurso; ethos, pathos e logos, pode-se considerar que a dimensão do ethos é, naturalmente, aquela que concentra as características mais relevantes do uso de celebridades em comunicação.

Segundo Meyer (2007: 34) o ethos é "a imagem de si, o caráter, a personalidade, os traços de comportamento a escolha de vida e dos fins (daí a palavra ética)". Ali se encontram as características da empresa, sua filosofia, seu estilo, ou como preferem chamar os teóricos da administração de empresas, sua visão, missão e valores. Como empresas são entidades intangíveis, é fundamental para distingui-las da concorrência que na comunicação seja criada uma personalidade para a marca. Ao menos em seu aspecto de personalidade, é possível desenhar a sua personalidade e construir seu sistema de comunicação baseado nas características projetadas para figurarem como ethos dessa empresa.

Dentre as características que compõem o ethos de uma empresa temos o orador, aquele que transmite a informação ao auditório. No complexo sistema de comunicação, em que não podem deixar de ser considerados elementos componentes da construção do 
orador o meio e a mensagem (MCLUHAN, 1971) iremos enfocar no orador propriamente dito, tornado tangível pela escolha criativa da agência de propaganda ao contratar uma pessoa que represente a marca anunciante, que seja sua imagem e voz. Essa representação ocorre quando a empresa se utiliza de uma personalidade para apresentar sua marca ou seu produto. Esse orador é o que mais se assemelha ao original, considerado por Aristóteles (2002), que fala ao auditório e empresta sua personalidade, sua relevância, sua credibilidade ao produto ou marca anunciada. Meyer (2007) explicita quem é esse orador:

É alguém que deve ser capaz de responder às perguntas que suscitam debate e que são aquilo sobre o que negociamos. Essa capacidade é um saber específico: o médico deve poder responder às perguntas médicas, o advogado, às perguntas jurídicas e assim por diante. Espera-se que eles respondam bem, pois estudaram para tal; quando quem se expressa não é nem advogado nem médico, mas simplesmente um ser humano seu "saber específico" refere-se a poder responder bem enquanto homem, sua virtude já não sendo mais a de um especialista, mas a virtude em geral, um ethos compartilhado por todos, em que cada um deve poder se reconhecer e ao qual pode se identificar (MEYER, 2007: 34).

Nota-se então que já existe aqui uma importante distinção: há os que sabem sobre o assunto, são especialistas e por isso devemos confiar no que dizem e há aqueles que não são especialistas e nossa confiança em relação a eles baseia-se tão somente da imagem que temos deles como pessoas.

O ethos é o orador como princípio (e também como argumento) de autoridade. A ética do orador é seu "saber específico" de homem, e esse humanismo é sua moralidade, que constitui fonte de autoridade. (MEYER, 2007: 35)

Essa visão de um orador com ethos construído a partir de um conhecimento específico ou de sua autoridade, referente a um histórico de atitudes aprovadas socialmente pode ter seu similar no uso publicitário que se faz de celebridades para anunciar produtos. Nessa perspectiva entendemos que existem "ethos" e "ethos", ou seja, há aqueles que efetivamente emprestam saberes ou características de personalidade que apoiam adequadamente uma marca e há aqueles que emprestam apenas sua celebridade, ou espetaculosidade vazia para marcas anunciantes. Assim, parece-nos lícito entender que seja possível estabelecer uma escala de valor para as diferentes autoridades que circulam no meio publicitário emprestando sua credibilidade para as marcas. 
Propomos então três níveis de autoridade nos quais pode-se encaixar as celebridades em função de sua credibilidade ou de sua capacidade de tornarem-se modelos a serem seguidos, ou emitirem opinião a ser respeitada pelo público alvo da marca anunciante.

Por outro lado, no universo da praxis publicitária, até onde sabemos, não são esses os critérios que guiam as agências de propaganda quando da escolha da persona ou da definiçãa do valor de seu cachê. Agências de publicidade tendem a considerar mormente a exposição midiática como fator determinante para a "grandeza" da celebridade, e o volume de mídia que será comprado para a definição do cachê. Assim, uma pessoa que esteja nas festas badaladas, nas revistas de fofocas, nos programas televisivos de entretenimento será preferencialmente a celebridade utilizada para anunciar o produto, não obstando o fato da personalidade da pessoa nada ter a ver com o branding da marca anunciante.

A definição do cachê costuma seguir o raciocínio de mídia, o mesmo utilizado pelos bancos de imagem, que alugam fotos para ilustração publicitária. Então o que se contrata é a imagem daquela pessoa para veiculação por tantos meses, nas tais mídias, garantindo-se a exclusividade na categoria de produtos anunciado. A guisa de exemplo, digamos que utilizaremos uma pessoa, vitoriosa em um reality show para anunciar eletrodomésticos por 3 meses em TV e revista. Não há nessa linha de raciocínio nenhuma preocupação com as características de autoritas da celebridade. Não se verifica, por exemplo, se no reality show que catapultou essa pessoa para o mundo das celebridades, ela se sobressaiu como, por exemplo, a cozinheira do grupo, demonstrando habilidade com eletrodomésticos que lhe daria autoridade para anunciar o produto ao final do programa. Não, o sistema é bem menos sofisticado, ou menos conectado com os princípios de ethos validados em 2 milênios de estudos e práticas de retórica.

Entendemos que o correto seria trazer para o universo publicitário o conhecimento que redundará em maior eficácia da ferramenta autoridade na medida em que as celebridades escolhidas se mostrem mais críveis aos olhos dos consumidores, resgatando assim a relevância da publicidade, ao menos nesse quesito.

Entendemos então que podem ser estabelecidos três níveis de autoridade no ethos das celebridades quando associadas às marcas na publicidade. Um primeiro nível é o que chamamos de "Autoridade Stricto" à qual se alinham dois tipos possíveis de 
autoridades: os "Institucionalmente Acreditados", ou seja, aquelas instituições ou pessoas que são oficialmente experts em determinados temas, como os dentistas sobre odontologia, ou a associação dos dentistas como elemento que outorga credibilidade para, por exemplo, uma nova marca de creme dental. Considera-se também autoridade stricto pessoas que tenham se sobressaído em uma atividade e que por essa "Performance" se tornaram autoridades. Pertencem a este grupo os grandes esportistas, os aventureiros e desbravadores, os cientistas, os intelectuais que se celebrizaram por suas conquistas, descobertas ou vitórias.

O segundo nível de autoridade é aquele ao qual chamamos "Autoridade Lato" que se refere àqueles que não são diretamente especialistas no assunto ou no produto ou serviço anunciado, mas que sua atividade, de alguma maneira tangencia os temas tratados pela marca. São modelos, atrizes, esportistas e demais autoridades em que o relacionamento entre características da pessoa e do produto anunciado encontram um ponto de convergência. Nesse nível de autoridade, a celebridade escolhida deve ter, em sua persona pública, características que possam ser associadas - ainda que de modo subjetivo - ao produto, serviço ou mensagem a ser veiculada.

Autoridades Lato comportam definições fugidias, pois estão mais ligadas à percepção que o público tem de determinada persona pública do que dos reais talentos e/ou feitos dessa pessoa. Por essa razão, as autoridades lato são sujeitas às manipulações signicas resultantes das interações midiáticas nas quais as celebridades interagem.

Finalmente chegamos ao mais rasteiro nível de autoridade o que chamamos "Autoridade Presença” que designariam celebridades que são conhecidas do público alvo, mas em que não há identidade entre as especialidades do personagem e as características do produto anunciado. Nessa categoria grassam as celebridades instantâneas e as marcas cujo marketing frágil sofre para construir imagens de marca sólidas distintas e relevantes, talvez também porque escolhem para seus garotos propaganda "personalidades sem personalidade". São modelos, cantores, vencedores de reality show, ou mesmo personalidades públicas ou do esporte que foram escolhidas para anunciar marcas, produtos e serviços apenas por sua celebridade e não por suas características distintivas. Seriam atrizes anunciando carros, jogadores de futebol anunciando produtos de beleza, chefs de cozinha anunciando telefonia celular...

Antes de encerrar o presente artigo é importante considerar que uma mesma celebridade pode se configurar, em momentos diferentes como os três tipos de 
autoridade, em função das características de sua identidade pública e dos produtos anunciados. Um astro de futebol, por exemplo, poderá ser considerado uma "autoridade stricto" quando estiver anunciando equipamento esportivo; esse mesmo jogador pode ser uma "autoridade lato" quando se trata de moda jovem, já que é jovem e em geral se veste com as marcas consideradas "da moda"; ele ainda poderá ser apenas "autoridade presença" quando anuncia, digamos, uma marca de sorvete, para o que não há qualquer correlação identitária possível.

\section{CONSIDERAÇÕES FINAIS}

Entende-se que tão mais eficaz será uma mensagem quanto mais crível for seu ethos. Além disso, é importante que esse ethos construído pelo sistema de comunicação das empresas torne a marca única aos olhos do consumidor e a faça sobressair diante dos concorrentes. $\mathrm{Na}$ sociedade do espetáculo em que vivemos, considera-se absolutamente lícito o uso das celebridades. Entretanto, seu uso indiscriminado pode levar a desgaste que pode tornar esse recurso retórico inócuo.

Não é novidade que a publicidade passa por uma crise estrutural, que tem a ver com outras questões, ligadas à revolução midiática causada pelo surgimento da internet. Mas o fato dos sistemas criativos insistirem em caminhos "fáceis", sem conhecimentos mais aprofundados dos processos persuasivos, pode ser, também, um fator relevante para a queda da eficiência da publicidade dentre as demais ferramentas de comunicação e marketing.

Nosso estudo teve por objetivo aproximar uma lente da questão do uso das celebridades para contribuir com o desenvolvimento dos sistemas de persuasão da comunicação brasileira. Se o processo de escolha das celebridades migrar, ou ao menos considerar, o fator de relevância da celebridade (stricto, lato, presença), em substituição à tradicional escolha a partir das mídias escolhidas, acredita-se que a eficácia do uso desse recurso deva aumentar.

\section{REFERÊNCIAS BIBLIOGRÁFICAS}


A HISTORY OF GRAPHIC DESIGN. Posters and Cult of Persnality. Disponível em $<$ http://guity-novin.blogspot.com.br/2010/05/chapter-30-posters-and-cultof.html>

ARISTÓTELES. Arte Retórica e Arte Poética. 15.ed. Rio de Janeiro: Ediouro, 2002.

ARNOULD, Eric J.; THOMPSON and CRAIG, J.. Consumer culture theory: Twenty years of research. Journal of Consumer Research. 31, 2005: 868-882.

BELCH, George E. Propaganda e Promoção: uma perspectiva de comunicação integrada de marketing. São Paulo. 7ª Ed. McGraw Hill, 2008.

CLUNAS, Craig. 1999. Modernity global and local: Consumption and the rise of the West. American Historical Review. 104:1497-1511.

DEBORD, Guy. A Sociedade do Espetáculo. Rio de Janeiro: Contraponto 1997.

HEIDER, E. Attitudes and cognitive organization. The Journal of Psychology. 21, 1989: 107-112.

JUNOKAITÉ, K.; ALIJOŠIENĖ, S.; GUDONAVIČIENĖ, R. İžymybių Atrankos Prekès Reklamai Sprendimai. Economics \& Management. 2007: 384-390.

LIU, M. T.; HUANG, Y. and SC MINGHUA, E. Relations among attractiveness of endorsers, match-up, and purchase intention in sport marketing in China. Journal of Consumer Marketing. 24(6). 2007: 358-365.

MCCRACKEN, G. Who is the celebrity endorser? Cultural foundation of the endorsement process. Journal of Consumer Research. 16(3), 1989: 310-321.

MEYER, M. A retórica. São Paulo: Ática, 2007.

MCLUHAN, M. Os Meios de Comunicação como Extensão do Homem. São Paulo: Cultrix, 1971.

MCGUIRE, W.J. The nature of attitudes and attitude change. In Lindsey, G. and Aronson, E. (Eds.) The Handbook of Social Psychology. 2nd Edition, Volume 3. Reading, MA: Addison-Wesley. Friedman and Friedman, 1979.

MISRA, S., SC BEATTY, S.E. Celebrity spokesperson and brand congruence: An assessment of recall. Journal of Business Research, 21(1), 159-171.Kamins \& Cupta, 1994; Till et al., 2008.

MOWEN, J.C. On Product Endorser Effectiveness: A Balance Model Approach. Current Issues \& Research in Advertising. 3(1), 1980: 41-57.

OHANIAN, R. Construction and validation of a scale to measure celebrity endorsers' perceived expertise. Journal of Advertising. 19(3), 1990: 39-52. 
Do uso de celebridades em publicidade

de Celso Figueiredo Neto e Yan Prado Lopes Silva

ROY, S.; GAMMOH, B.; and KOH, A. Predicting the effectiveness of celebrity endorsements using the balance theory. Journal Of Customer Behaviour. 11, 1, Business Source Complete, EBSCO host, viewed 7 August 2012: 33-52

RUIHLEY, B. J.; RUNYAN, R. C.; LEAR, K. E. Sport Marketing Quarterly. Vol. 19, Issue 3, 2010: 132

WENGROW, D. Prehistories of Commodity Branding. Current Anthropology. Vol. 49, No. 1. 2008: 7-34.

Artigo submetido: 28/07/2013

Artigo aprovado: 07/06/2014 